Association for Information Systems

AIS Electronic Library (AISeL)

Who Else do You Need for a Data-Driven Business Model?

Exploring Roles and Exchanged Values

Florian Leski

Michael Fruhwirth

Viktoria Pammer-Schindler

Follow this and additional works at: https://aisel.aisnet.org/bled2021

This material is brought to you by the BLED Proceedings at AIS Electronic Library (AISeL). It has been accepted for inclusion in BLED 2021 Proceedings by an authorized administrator of AIS Electronic Library (AISeL). For more information, please contact elibrary@aisnet.org. 


\title{
WHO ElSE do You NEED FOR A DATA- \\ DRIVEN BUSINESS MODEL? EXPLORING \\ Roles AND EXCHANGED VALUES
}

\author{
FLORIAN LESKI, ${ }^{1}$ MiCHAEL FRUHWIRTH ${ }^{2} \&$ \\ VIKTORIA PAMMER-SCHINDLER ${ }^{1}$ \\ ${ }^{1}$ Graz University of Technology, Graz, Austria, e-mail: florian.leski@student.tugraz.at, \\ viktoria.pammer-schindler@tugraz.at \\ ${ }^{2}$ Know-Center GmbH, Graz, Austria, e-mail: mfruhwirth@know-center.at
}

Abstract The increasing volume of available data and the advances in analytics and artificial intelligence hold the potential for new business models also in offline-established organizations. To successfully implement a data-driven business model, it is crucial to understand the environment and the roles that need to be fulfilled by actors in the business model. This partner perspective is overlooked by current research on datadriven business models. In this paper, we present a structured literature review in which we identified 33 relevant publications. Based on this literature, we developed a framework consisting of eight roles and two attributes that can be assigned to actors as well as three classes of exchanged values between actors. Finally, we evaluated our framework through three cases from one automotive company collected via interviews in which we applied the framework to analyze data-driven business models for which our interviewees are responsible.

Keywords: data-driven business models, ecosystem, framework, key partners, literature review 


\section{Introduction}

The increasing volume of available data and the advances in analytics and artificial intelligence hold the potential for competitive advantage, business growth, and new business models. Thus, also offline-established organizations are seeking new socalled data-driven business models (DDBMs). This innovation and transformation process is often challenging, as it requires new skills and capabilities (e.g., data science or IT infrastructure), deep relationships, and partner information ecosystems (Schüritz et al., 2017). These interdependencies and the complexity of the ecosystem increase the risk in business model innovation (Dellermann et al., 2017).

In general, tools and methods support the process of business model innovation. Still, there is a limited amount of tool support that explicitly focuses on data utilization and mainly supports idea generation (Fruhwirth, Ropposch, PammerSchindler, 2020). Furthermore, to successfully implement DDBMs, it is crucial to understand the environment and involved stakeholders, as companies will collaborate more and increase their dependencies (Hunke et al., 2017). Typically, traditional firms rely on new external partners for their DDBM, such as a cloud- or data provider. Thus, it is important to know the roles that need to be fulfilled by actors in the own business model. Business model representations with a transactional focus are useful to understand, develop, and model business models (Fruhwirth et al., 2021; Täuscher and Abdelkafi, 2017). There, types of actors and exchanged values support modeling a business model (Terrenghi et al., 2018). Despite this, existing research on DDBMs mostly overlooks the partner and ecosystem perspective. Accordingly, we ask the following research question: What roles do exist in a data-driven business model, and how can the exchanged values be categorized?

To answer this research question, we conducted a structured literature review and derived a framework with a set of eight roles and two attributes that can be assigned to actors as well as three classes of exchanged values. The framework was evaluated by applying it to three use cases from one company in the automotive industry. 


\section{$2 \quad$ Background}

Data-driven business models are digital business models with a conceptual focus on value creation with data (Guggenberger et al., 2020). DDBMs rely on data as a key resource and apply data analytics techniques as key activities to discover insights from data and that are transformed into a data-based value proposition that supports customers in their decision-making process (Hartmann et al., 2016; Kühne and Böhmann, 2019; Schüritz et al., 2019). Other researchers denote such models as »data-infused business models« (Schüritz and Satzger, 2016) or »data-driven services« (Azkan et al., 2020). Data-driven services could be either offered as standalone or as an add-on to existing products or services (Breitfuß et al., 2019; Wixom and Ross, 2017). Existing conceptualization and classification approaches of DDBMs have a company-centric focus, studying the value creation process with types of data sources and key activities related to data and analytics (e.g., Hartmann et al., 2016), the value proposition (e.g., Fruhwirth, Breitfuß, Pammer-Schindler, 2020) or the value delivery with service flows or platform types (e.g., Azkan et al., 2020). Studying and developing DDBMs also involves the ecosystem perspective with involved roles and actors (Hunke et al., 2017). Little attention has been paid to that in contemporary research on DDBMs.

A business model can be understood as san architecture of the product, service and information flows, including a description of the various business actors and their roles; a description of the potential benefits for the various business actors; a description of the sources of revenuesu (Timmers, 1998, p. 4). These actors are economic independent entities and »exchange value objects, which are services, products, money, or even consumer experiences. A value object is valuable to one or more actors." (Gordijn and Akkermans, 2001, p. 13). A business model also can be seen as a set of activities, performed by the focal organization itself, by its customers, suppliers, and/or partners (Zott and Amit, 2010). Thus, every actor has one or more roles, that describe an actor's activities, functions, or contributions in the business model (Terrenghi et al., 2018). This understanding of business models takes a network-centric and transactional view, focusing on value exchange among actors. Similar concepts in that regard have been established, such as the »value network« (Allee, 2008), or the »business ecosystem« (Jacobides et al., 2018). 


\section{Methodology}

Aiming to identify types of actors and classes of exchanged values in DDBMs, we conducted a structured literature review and adopted an inductive category formation approach to analyze and synthesize the literature. Finally, we evaluated our framework in three cases from one automotive company.

We based our search and selection process on the guidelines and recommendations of Vom Brocke et al. (2009) and Webster and Watson (2002). We started with a database search as summarized in Table 1. Our search strings were informed by previous literature denoted in the background section. We searched separately for papers dealing with actors and exchanged values in ecosystems. By applying the stated logical search terms in the respective databases ${ }^{1}, 2513$ articles were found; 917 for actors, 1496 regarding exchanged values.

Table 1: Summary of the Database Search Results

\begin{tabular}{|c|c|c|c|c|c|c|c|c|}
\hline & & & $\begin{array}{l}\overline{\mathscr{U}} \\
\stackrel{\mathscr{Z}}{4}\end{array}$ & 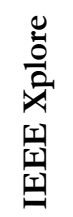 & 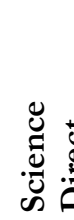 & 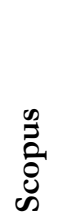 & & $\sum_{U}$ \\
\hline \multirow{2}{*}{$\begin{array}{l}\text { ("digital" OR "data- } \\
\text { driven" OR "data- } \\
\text { infused" OR "data- } \\
\text { based") AND } \\
\text { ("business model" OR } \\
\text { "service") }\end{array}$} & \multirow[b]{2}{*}{ AND } & $\begin{array}{l}\text { (role" OR } \\
\text { "actor" OR } \\
\text { "partner") }\end{array}$ & 300 & 22 & 230 & 162 & 118 & 85 \\
\hline & & $\begin{array}{l}\text { ("network" } \\
\text { OR } \\
\text { "ecosystem" } \\
\text { OR "value } \\
\text { chain") }\end{array}$ & 281 & 214 & 258 & 306 & 193 & 244 \\
\hline
\end{tabular}

Further, we applied a three-step selection process: First, we selected 119 relevant articles based on their titles. Second, we scanned the abstracts of these selected papers for relevance, limiting them to 62 articles. Third, we read the full text of the remaining papers and made a final selection of 26 articles that are relevant for our

\footnotetext{
${ }^{1}$ Search strings were applied to title, abstract, keywords and/or full text depending on the database to retrieve a manageable number of articles per query. A detailed description can be provided by the authors upon request.
} 
research. We also conducted a forward and backward search (Webster and Watson, 2002), leading to an additional set of 11 publications. Therefore, we arrived at a final sample of 38 articles (17 for actors, and 21 for exchanged values), whereas five articles were present in both categories, resulting in 33 articles $^{2}$ without overlaps.

After the search and selection process, we analyzed and synthesized the selected literature following an inductive category formation approach (Mayring, 2015). We examined the papers' content aiming to define distinct roles for actors and classes of exchanged values present in DDBMs. Initially, we specified that the level of abstraction of the resulting classes must be generic so that they can be applied to a broad spectrum of industries. We analyzed the material focusing on the results, findings, conclusions, figures, and tables and summarized the essential parts of the material for both actors and exchanged values. Subsequently, we synthesized this interim outcome to a generic set of categories, consisting of ten roles and two attributes that can be assigned to actors as well as three classes of exchanged values. After the evaluation, two roles were dropped or merged with other roles.

We evaluated and refined our framework in three use cases from the automotive industry. Therefore, we conducted three semi-structured interviews with managers from one automotive company (as shown in Table 2), each responsible for developing a business model for a data-driven innovation. We selected only cases where a data-driven service was provided to external B2B customers. To ensure the confidentiality of the company, interviewees, and use cases, all names and specific information were anonymized. In the beginning, we introduced the framework of roles and classes of exchanged values. The interviewees were then asked to apply the framework in the context of their use cases, in terms of involved actors as well as exchanged values. The outcome of each interview was a visual network-based representation of the business model. Further, we asked how understandable, useful and comprehensive the framework is and if some roles were missing or unnecessary.

\footnotetext{
2 The full list of identified articles was omitted in this paper due to space restrictions and can be provided by the authors upon request.
} 
Table 2: Overview of interviews

\begin{tabular}{|c|l|l|c|}
\hline & Position & Use Case & Duration \\
\hline A & Product Manager & Service in the field of autonomous driving & $45 \mathrm{~min}$ \\
\hline B & Product Manager & Providing end-customer insights as a service & $30 \mathrm{~min}$ \\
\hline C & Project Manager & Fleet monitoring service for electric vehicles & $45 \mathrm{~min}$ \\
\hline
\end{tabular}

\section{$4 \quad$ Results}

In the following, we present our framework, as shown in Figure 1, by introducing eight roles and two attributes that can be assigned to an actor and follow with three classes of values that are exchanged between actors. Note that we describe here only the final framework after performing the initial evaluation described later in Section 5 due to space limitations.
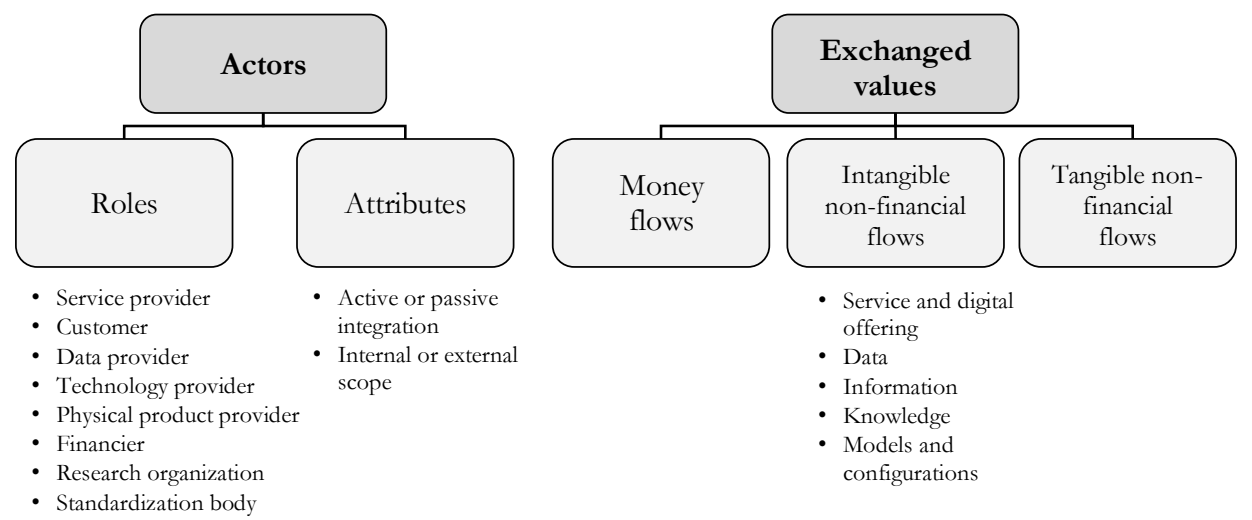

Figure 1: Classification of actors and exchanged values in data-driven business models.

\subsection{Roles of Actors in Data-Driven Business Models}

We have identified eight different roles that can be assigned to an actor in a DDBM:

- A service provider is an actor who utilizes data as a resource to create or co-create value for other actors (Immonen et al., 2014; Kaiser et al., 2019; Schüritz et al., 2019), for instance, by adding data-driven services to a physical product (Terrenghi et al., 2018). 
- A customer is a recipient of the offering who also has a need. The customer initiates the value generation process triggered by his needs (Terrenghi et al., 2018), can actively participate in the value (co-)creation (Cova and Salle, 2008), or act just as a passive receiver. A customer creates real value via utilizing the potential value of the data-driven service offered by the service provider (Schüritz et al., 2019).

- A data provider is an actor who collects and aggregates data from public or private sources, performs the necessary preprocessing steps, and provides it to other actors who request data (Curry, 2016). This includes for instance collecting data about the conditions of a physical object in a cyberphysical system (Terrenghi et al., 2018).

- A technology provider is an actor who provides the necessary technical infrastructure, platforms, and tools to the business model owner, such as data management solutions or cloud technology (e.g., Curry, 2016; Immonen et al., 2014)

- A physical product provider is an actor who manufactures and sells a physical core product equipped with data-collecting devices, such as sensors, that should be enriched with a data-driven service (Kaiser et al., 2019; Papert and Pflaum, 2017; Terrenghi et al., 2018).

- A financier is a provider of financial resources for the business model innovation, such as a pre-financing investor, an incubator, or a venture capitalist (Curry, 2016; Papert and Pflaum, 2017).

- A research organization, such as a university, a research partner, or an internal research and development department, is an actor that engages with other actors in the business model to support the value generation process (Kindström et al., 2015; Schymanietz and Jonas, 2020).

- A standardization body is responsible for introducing common standards and controlling the economy legally addressing topics such as transparency or data privacy in the ecosystem (Curry, 2016; Terrenghi et al., 2018).

\subsection{Actor Attributes}

We further found two attributes that can be assigned to each actor describing their interaction in the business model: the level of integration into the business model (i.e., active or passive) and the scope (i.e., internal or external). 
The integration of an actor into the business model can be either active or passive. An actively integrated actor can benefit from working with other actors in the business model (Zolnowski et al., 2016). Turetken et al. (2019) distinguish between core partners that are actively engaged in the value creation process; and enriching partners. The focal organization is overseeing the business model and takes an active role. Also, a customer can play an active role in the value co-creation process of a data-driven service (Schüritz et al., 2019) or stay passive by just receiving an offering.

The scope describes the internal or external relation relative to the focal business model that is currently analyzed. A service ecosystem consists of internal and external roles (Sklyar et al., 2019). All actors that are clustered within the same organizational unit of the focal business model are considered as internal. The business model owner cannot run the business by himself alone and therefore is usually supported by external and internal actors (Schymanietz and Jonas, 2020). For instance, a DDBM can rely on internal data sources, external data sources, or both (Hartmann et al., 2016), thus involves also external data providers.

\subsection{Exchanged Values between Actors}

Actors are exchanging values in a DDBM, that we clustered into three classes: money flows, intangible non-financial flows, and tangible non-financial flows.

Money flow summarizes all exchanged values of financial nature. Money serves as an enabler for negotiation and trading activities between economic actors (Allee, 2008). Flows of money can occur in different forms, denoted as revenue models, such as subscription fees or a pay-per-use model (Terrenghi et al., 2018). The choice of one model is influenced by several factors, such as capabilities and the characteristic of the service (Enders et al., 2019).

The class of intangible non-financial flow summarizes all exchanged values between actors that are non-monetary and intangible meaning that it »cannot be seen, felt, tasted or touched « (Chowdhury and Åkesson, 2011, p. 4). Such values are denoted in general as services (e.g., Immonen et al., 2014; Täuscher and Laudien, 2017) and digital offerings (Sklyar et al., 2019; Täuscher and Laudien, 2017). On a more granular level, flows can be divided into data (e.g., Engelbrecht et al., 2016; Terrenghi et al., 2018), information (e.g., Curry, 2016; Schüritz et al., 2019), 
knowledge (e.g., Brownlow et al., 2015; Schüritz et al., 2019), and models or configuration of models (Hirt and Kühl, 2018).

The category tangible non-financial flow summarizes all exchanged values between actors that are non-monetary and tangible, such as physical products, raw materials, or other physical resources (e.g., Allee, 2008; Täuscher and Laudien, 2017). DDBMs can also rely on hardware as a key resource, such as measurement instruments, data transmission devices, or data-generating products.

\section{$5 \quad$ Evaluation and Discussion of Results in three Cases}

We evaluated the initial framework from the literature synthesis in three cases, collected via interviews with managers from one automotive company. We structured our insights along with the findings from the cases and the interviewees' feedback regarding the completeness, discriminability, and understandability of the individual elements as well as the usefulness of the overall framework.

The framework was sufficient to describe and analyze the cases: all roles, attributes, and values of the framework appeared in the cases and no additional ones that were not included in the framework emerged through the data collection process. When analyzing the content of our cases, we found that in two of three cases, one actor in the business model fulfilled both roles of the customer as well as a data provider, because the business model was relying on data provided by the customer. Further, the business models relied on partners with the role of a technology provider (e.g., providing a platform for data analysis), as well as a physical product provider (e.g., providing measurement hardware for data acquisition as well as devices for storage and transmission). Also, the attribute scope has been helpful in distinguishing between roles that are fulfilled internally and by external partners in the business model. Regarding the completeness of the framework, one interviewee mentioned that it is "quite comprehensive, I can't think of an actor that is missing" (Interviewee A). Interviewee $\mathrm{C}$ mentioned that he missed the role of the user, as in $\mathrm{B} 2 \mathrm{~B}$ context, the user and buying customer are often separate actors within one organization.

Regarding the definition of roles, we found that the initial roles of »data supplier« and »data collector « were difficult to distinguish, as one interviewee mentioned: »the differentiation between the collector and supplier is diffuse for me, it might make more sense for other use cases (Interviewee A). Therefore, we decided to merge both under a new role 
»data provider«. Similarly, distinguishing the initial roles of »resource integrator«, »service provider« and »technology provider« was challenging. We decided to drop the role of "resource integrator « and refined the definition of a technology provider, in the sense that a technology provider only offers the resource without supporting the application of it compared to a service provider. Further, the interviewees found it beneficial to have a more nuanced level of integration. We found that it is necessary to elaborate a more granular differentiation of exchanged intangible values, for instance what distinct type of exchanged data in a DDBM is essential.

Regarding the usefulness of the framework, it could help to understand complex environments by illustrating all involved actors as a whole. Interviewee B for instance, mentioned that a visual representation with this framework could be beneficial in complex and multi-layered business models and wwhere there are no flows on both sides, it is critical because only one actor can benefit from the setting" (Interviewee B).

\section{Conclusion}

In this research, we developed a framework with roles and attributes that can be assigned to actors and classes of values exchanged between actors in DDBMs. We contribute to the body of knowledge by shedding first lights on the partner perspective in DDBMs, which was overlooked by previous research. We extend the existing research of Hunke et al. (2020) on the orchestration of key activities in datadriven services, by a nuanced reflection of the partner perspective. Further, our framework extends a network-based representation for DDBMs from Fruhwirth et al. (2021) by providing a template for identifying and then visualizing relevant actors and value flows. Additionally, we extend existing research on flow-based business model representations (e.g., Gordijn and Akkermans, 2001) by introducing new attributes for actors as well as data as a central type of value flows.

Note as a limitation, that we found few publications that had a specific focus on data due to the topic's novelty. Further, we might have missed some literature due to the difference in the denomination of the concept of DDBMs that our search strings might not cover. Another limitation is the sparse evaluation of the results only via three experts of one company in one particular industry. To further improve our framework, it should be applied to an additional number of cases from multiple industries to make our results more generalizable. Also, a detailed investigation of 
data-related value exchanges and the roles of service and technology providers seems like a fruitful direction for further research. Further, the framework could be instantiated in a tool with visual representations of the actors and values to design and communicate DDBMs.

\section{References}

Allee, V. (2008) 'Value network analysis and value conversion of tangible and intangible assets', Journal of Intellectual Capital, vol. 9, no. 1, pp. 5-24.

Azkan, C., Iggena, L., Gür, I., Möller, F. and Otto, B. (2020) 'A Taxonomy for Data-Driven Services in Manufacturing Industries', PACIS 2020 Proceedings.

Breitfuß, G., Fruhwirth, M., Pammer-Schindler, V., Stern, H. and Dennerlein, S. (2019) 'The DataDriven Business Value Matrix: A Classification Scheme for Data-Driven Business Models', 32nd Bled eConference Humanizing Technology for a Sustainable Society, pp. 803-820.

Brownlow, J., Zaki, M., Neely, A. and Urmetzer, F. (2015) Data and Analytics - Data-Driven Business Models: A Blueprint for Innovation [Online], Cambridge Service Alliance. Available at http://cambridgeservicealliance.eng.cam.ac.uk/resources/Downloads/Monthly\%20Papers/2 015FebruaryPaperTheDDBMInnovationBlueprint.pdf (Accessed 19 July 2017).

Chowdhury, S. and Åkesson, M. (2011) 'A proposed conceptual framework for identifying the logic of digital services', PACIS 2011 Proceedings.

Cova, B. and Salle, R. (2008) 'Marketing solutions in accordance with the S-D logic: Co-creating value with customer network actors', Industrial Marketing Management, vol. 37, no. 3, pp. 270-277.

Curry, E. (2016) 'The Big Data Value Chain: Definitions, Concepts and Theoretical Approaches', in Cavanillas, J. M., Curry, E. and Wahlster, W. (eds) New horizons for a data-driven economy: A roadmap for usage and exploitation of big data in Europe, Switzerland, SpringerOpen, pp. 29-38.

Dellermann, D., Fliaster, A. and Kolloch, M. (2017) 'Innovation risk in digital business models: the German energy sector', Journal of Business Strategy, vol. 38, no. 5, pp. 35-43.

Enders, T., Schüritz, R. and Frey, W. (2019) 'Capturing Value from Data: Exploring Factors Influencing Revenue Model Design for Data-Driven Services’, WI 2019 Proceedings, pp. 1738-1752.

Engelbrecht, A., Gerlach, J. and Widjaja, T. (2016) Understanding the anatomy of data driven business models - towards an empirical taxonomy', ECIS 2016 Proceedings.

Fruhwirth, M., Breitfuß, G. and Pammer-Schindler, V. (2020) 'The Data Product Canvas: A Visual Collaborative Tool for Designing Data-Driven Business Models', 33rd Bled eConference Enabling Technology for a Sustainable Society. Online, June 28-29 2020, pp. 515-528.

Fruhwirth, M., Pammer-Schindler, V. and Thalmann, S. (2021) 'A Network-based Tool for Identifying Knowledge Risks in Data-Driven Business Models', Proceedings of the 54th Annual Hawaii International Conference on System Sciences, pp. 5218-5227.

Fruhwirth, M., Ropposch, C. and Pammer-Schindler, V. (2020) 'Supporting Data-Driven Business Model Innovations: A structured literature review on tools and methods', Journal of Business Models, vol. 8, no. 1, 7-25.

Gordijn, J. and Akkermans, H. (2001) 'Designing and evaluating e-business models', IEEE Intelligent Systems, vol. 16, no. 4, pp. 11-17.

Guggenberger, M. T., Möller, F., Boualouch, K. and Otto, B. (2020) 'Towards a Unifying Understanding of Digital Business Models', PACIS 2020 Proceedings.

Hartmann, P. M., Zaki, M., Feldmann, N. and Neely, A. (2016) 'Capturing value from big data - a taxonomy of data-driven business models used by start-up firms', International Journal of Operations \& Production Management, vol. 36, no. 10, pp. 1382-1406. 
Hirt, R. and Kühl, N. (2018) 'Cognition in the Era of Smart Service Systems: Inter-organizational Analytics through Meta and Transfer Learning', ICIS 2018 Proceedings.

Hunke, F., Seebacher, S., Schüritz, R. and Illi, A. (2017) 'Towards a Process Model for Data-Driven Business Model Innovation', 19th IEEE Conference on Business Informatics, pp. 150-157.

Hunke, F., Seebacher, S. and Thomsen, H. (2020) 'Please Tell Me What to Do - Towards a Guided Orchestration of Key Activities in Data-Rich Service Systems', DESRIST 2020 Proceedings.

Immonen, A., Palviainen, M. and Ovaska, E. (2014) 'Requirements of an Open Data Based Business Ecosystem', IEEE Access, vol. 2, pp. 88-103.

Jacobides, M. G., Cennamo, C. and Gawer, A. (2018) 'Towards a theory of ecosystems', Strategic Management Journal, vol. 39, no. 8, pp. 2255-2276.

Kaiser, C., Stocker, A. and Fellmann, M. (2019) 'Understanding Data-driven Service Ecosystems in the Automotive Domain', AMCIS 2019 Proceedings.

Kindström, D., Kowalkowski, C. and Alejandro, T. B. (2015) 'Adding services to product-based portfolios', Journal of Service Management, vol. 26, no. 3, pp. 372-393.

Kühne, B. and Böhmann, T. (2019) 'Data-Driven Business Models: Building the Bridge Between Data and Value', ECIS 2019 Proceedings.

Mayring, P. (2015) Qualitative Inhaltsanalyse: Grundlagen und Techniken, 12th edn, Weinheim, Beltz.

Papert, M. and Pflaum, A. (2017) 'Development of an Ecosystem Model for the Realization of Internet of Things (IoT) Services in Supply Chain Management', Electronic Markets, vol. 27, no. 2, pp. 175-189.

Schüritz, R., Farrell, K., Wixom, B. H. and Satzger, G. (2019) 'Value Co-Creation in Data-Driven Services: Towards a Deeper Understanding of the Joint Sphere', ICIS 2019 Proceedings.

Schüritz, R. and Satzger, G. (2016) 'Patterns of Data-Infused Business Model Innovation', IEEE 18th Conference on Business Informatics, pp. 133-142.

Schüritz, R., Seebacher, S., Satzger, G. and Schwarz, L. (2017) 'Datatization as the Next Frontier of Servitization: Understanding the Challenges for Transforming Organizations', ICIS 2017 Proceedings.

Schymanietz, M. and Jonas, J. M. (2020) 'The Roles of Individual Actors in Data-Driven Service Innovation - A Dynamic Capabilities Perspective to Explore its Microfoundations', Proceedings of the 53rd Annual Hawaii International Conference on System Sciences (HICSS 2020), pp. 1135-1144.

Sklyar, A., Kowalkowski, C., Tronvoll, B. and Sörhammar, D. (2019) 'Organizing for digital servitization: A service ecosystem perspective’, Journal of Business Research, vol. 104, pp. 450 460.

Täuscher, K. and Abdelkafi, N. (2017) 'Visual tools for business model innovation: Recommendations from a cognitive perspective', Creativity and Innovation Management, vol. 26, no. 2, pp. 160 174.

Täuscher, K. and Laudien, S. M. (2017) 'Uncovering the Nature of Platform-based Business Models: An Empirical Taxonomy', Proceedings of the 50th Hawaii International Conference on System Sciences.

Terrenghi, N., Schwarz, J. and Legner, C. (2018) 'Towards Design Elements to Represent Business Models for Cyber Physical Systems’, ECIS 2018 Proceedings.

Timmers, P. (1998) 'Business Models for Electronic Markets', Electronic Markets, vol. 8, no. 2, pp. 3 8.

Turetken, O., Grefen, P., Gilsing, R. and Adali, O. E. (2019) 'Service-Dominant Business Model Design for Digital Innovation in Smart Mobility', Business \& Information Systems Engineering, vol. 61, no. 1, pp. 9-29.

Vom Brocke, J., Simons, A., Niehaves, B., Niehaves, B., Reimer, K., Plattfaut, R. and Cleven, A. (2009) 'Reconstructing the Giant: On the Importance of Rigour in documenting the Literature Search Process', ECIS 2009 Proceedings.

Webster, J. and Watson, R. T. (2002) 'Analyzing the past to prepare for the future: Writing a literature review', Management Information Systems Quarterly, vol. 26, no. 2, pp. 13-23. 
Wixom, B. H. and Ross, J. W. (2017) 'How to Monetize Your Data', MIT Sloan Management Review, vol. 58 , no. 3, pp. 10-13.

Zolnowski, A., Towe, C. and Gudat, J. (2016) 'Business Model Transformation Patterns of DataDriven Innovations', ECIS 2016 Proceedings.

Zott, C. and Amit, R. (2010) 'Business Model Design: An Activity System Perspective', Long Range Planning, vol. 43, 2-3, pp. 216-226 
